\title{
Silica exposure and altered regulation of autoimmunity
}

\author{
Suni Lee $\cdot$ Hidenori Matsuzaki $\cdot$ Naoko Kumagai-Takei $\cdot$ Kei Yoshitome $\cdot$ \\ Megumi Maeda $\cdot$ Ying Chen - Masayasu Kusaka $\cdot$ Kozo Urakami · \\ Hiroaki Hayashi · Wataru Fujimoto $\cdot$ Yasumitsu Nishimura $\cdot$ Takemi Otsuki
}

Received: 30 April 2014/Accepted: 31 July 2014/Published online: 19 August 2014

(C) The Japanese Society for Hygiene 2014

\begin{abstract}
Silica particles and asbestos fibers, which are known as typical causatives of pneumoconiosis, induce lung fibrosis. Moreover, silicosis patients often complicate with autoimmune diseases, and asbestos-exposed patients suffer from malignant diseases such as pleural mesothelioma and lung cancer. We have been conducting experimental studies to investigate altered regulation of selftolerance caused by silica exposure, including analyses using specimens such as plasma and immunocompetent cells obtained from silicosis patients, as a means of examining the supposition that silica exposure induces molecular and cellular biological alterations of immune
\end{abstract}

S. Lee $\cdot$ H. Matsuzaki $\cdot$ N. Kumagai-Takei $\cdot$ K. Yoshitome

Y. Nishimura · T. Otsuki ( $₫)$

Department of Hygiene, Kawasaki Medical School,

577 Mastushima, Kurashiki 701-0192, Japan

e-mail: takemi@med.kawasaki-m.ac.jp

M. Maeda

Division of Bioscience, Department of Biofunctional Chemistry,

Okayama University Graduate School of Natural Science and

Technology, 1-1-1 Tsushimanaka, Kita-Ku, Okayama 700-8530,

Japan

\section{Y. Chen}

Division of Pneumoconiosis, School of Public Health, China

Medical University, 92 North 2nd, Heping District,

Shenyang 110001, People's Republic of China

\section{Kusaka}

Kusaka Hospital, 1122 Nishikatagami, Bizen 705-0121, Japan

K. Urakami

Hinase Urakami Iin, 243-4 Hinase, Hinase-cho, Bizen 7013204, Japan

H. Hayashi · W. Fujimoto

Department of Dermatology, Kawasaki Medical School, 577

Mastushima, Kurashiki 701-0192, Japan cells. These approaches have resulted in the detection of several specific autoantibodies, alterations of CD95/Fas and its related molecules, and evidence of chronic activation of responder $\mathrm{T}$ cells and regulatory $\mathrm{T}$ cells following silica exposure. In this review, we present details of our investigations as an introduction to scientific approaches examining the immunological effects of environmental and occupational substances.

Keywords Silica - Silicosis - Autoimmune - CD95/Fas . Apoptosis $\cdot$ Regulatory $\mathrm{T}$ cell

\section{Introduction}

Silica particles and asbestos fibers are known as typical environmental and occupational causatives of pneumoconiosis [1, 2]. In addition to occupational exposure, studies have documented the impact of asbestos exposure from the environment such as the rubble resulting from an earthquake or areas surrounding building demolition sites [3, 4].

Patients with pneumoconiosis suffer not only with respiratory complications such as chronic bronchitis, emphysema and lung fibrosis, but also from autoimmune disorders in the case of silicosis patients and malignant tumors such as pleural mesothelioma and lung cancer in the case of asbestosis patients. The typical autoimmune disorders complicated with silicosis include rheumatoid arthritis (well known as Caplan syndrome) [5, 6], systemic lupus erythematosus (SLE) [7, 8], systemic sclerosis (SSc) $[9,10]$, and anti-neutrophil cytoplasmic antibody (ANCA)related vasculitis [11-14].

Although the biological mechanisms of silica-induced altered regulation of autoimmunity have been considered adjuvant effects of silica particles [15], we have been 
investigating the supposition that silica particles directly alter the cellular and molecular biological characteristics of immunocompetent cells due to chronic and recurrent encounters at the lung and intra-pulmonary lymph nodes, and that these alterations of immune cells may cause these cells to gradually progress toward the disruption of autoimmune tolerance [16-19].

In this review, we introduce experimental investigations using specimens such as plasma and freshly isolated lymphocytes derived from silicosis patients, and discuss the various mechanisms of silica-induced altered regulation of autoimmunity.

All experiments using clinical specimens were approved by the ethics committee of the Kawasaki Medical School, and all specimens were taken from patients who provided documented informed consent. All silicosis patients investigated were brickyard workers in Bizen City, Okayama Prefecture, Japan, and were diagnosed with silicosis according to guideline ILO 2000 [20]. These patients did not manifest any clinical symptoms of autoimmune diseases or malignant tumors.

\section{Findings for altered regulation of autoimmunity in silicosis}

\section{Autoantibodies detected}

It is well known that silicosis patients often exhibit higher titers of autoantibodies. Our studies corroborate this tendency and revealed that silicosis patients show higher titers of anti-nuclear antibodies (ANA) compared with that of healthy donors $[21,22]$. Furthermore, we discovered several specific autoantibodies in silicosis patients.

Our investigations first detected anti-topoisomerase I autoantibody (also known as anti-Scl-70 autoantibody) in silicosis patients [23-26]. This autoantibody is known as the marker for lung fibrosis, diffuse sclerotic skin, and peripheral vasculitis in SSc patients. In addition, the detection of this autoantibody is known to be associated with particular HLA types, such as DQB1-0301 in the Caucasian population and DQB1:0601 in the Japanese population. We found that silicosis patients who were positive for anti-topoisomerase I autoantibody showed a higher frequency of DQB1:0402.

We next detected anti-CD95/Fas autoantibody in one quarter of silicosis patients [27]. The CD95/Fas molecule is well known as a cell death receptor that causes apoptosis, which is particularly important in lymphocytes [28, 29]. The genetic alteration of Fas and its ligand (Fas ligand) is known as autoimmune lymphoproliferative (ALPS) syndrome $[30,31]$. The non-functional Fas may cause longer survival of responder $\mathrm{T}$ lymphocytes, which may react with self/non-self antigens, and the long survival may induce clinical symptoms of inflammatory reactions with self/nonself antigens. In addition to the detection of anti-Fas autoantibody in silicosis patients, we investigated whether this anti-Fas autoantibody was functional for apoptosis, since the serum from patients whose titer of anti-Fas autoantibody was the highest induced the reduction of proliferation of a Fas-expressing human myeloma cell line. However, this phenomenon was not observed in a non-Fasexpressing human myeloma cell line (a sister myeloma cell line derived from the same patient of the abovementioned Fas-expressing myeloma cell line) [27].

A consideration of Fas-mediated apoptosis shows that caspase- 8 is the key molecule that causes DNA fragmentation in Fas-mediated apoptosis [32, 33]. Once Fas was activated with the Fas ligand, initiator caspases (such as caspase 8,10 and 2) were activated and then sent signals to effector caspases (such as 3,6 and 7), and processing molecules for DNA fragmentation were then activated. We found the anti-caspase 8-autoantibody among these factors in silicosis patients. It was then demonstrated that the positivity of this autoantibody was also related to specific HLA types, such as DRB1, DQB1 and DPB1 alleles $[34,35]$.

We also reported silicosis patients who were positive for anti-desmoglein autoantibody, and these patients were usually positive if possessing pemphigus vulgaris but without any symptoms of bullous diseases [36].

All of these findings indicate there is altered regulation of autoimmunity in silicosis patients, and one of the manifestations of autoimmune disorders in silicosis involves the presence of many autoantibodies in silicosis patients. These findings may suggest the altered regulation of autoimmunity of immune cells in silicosis.

\section{Alteration of Fas and Fas-related molecules}

As mentioned above, the Fas molecule is very important in regulating the fate of lymphocytes and associated apoptosis. Physiologically, the activated T lymphocytes due to the self/non-self antigens should terminate their activation and be excluded by apoptosis (activation-induced cell death; AICD), which is mainly caused by Fas-mediated apoptosis $[37,38]$. Thus, if the Fas-mediated apoptosis was inhibited by certain factors, some $\mathrm{T}$ cell clones which may react with self-antigens would survive for a longer period and thereby create the basic conditions for the occurrence of clinical manifestations of autoimmune disorders.

For example, a typical alternative spliced form of the Fas molecule with the deleted transmembrane domain is known as soluble Fas. Soluble Fas is secreted from cells into the surrounding area and binds with the Fas ligand before the Fas ligand reaches membrane Fas [39, 40]. Thus, 
Fas-mediated apoptosis is inhibited. There are several studies that show some autoimmune diseases exhibit higher serum levels of the soluble Fas molecule compared with healthy donors [41-44].

We therefore measured the serum level of soluble Fas in silicosis patients, and our results revealed significantly higher levels in these patients compared to those of healthy donors [45]. Furthermore, mRNA expression of soluble Fas in peripheral blood mononuclear cells (PBMC) derived from silicosis patients was significantly higher compared to that of healthy donors [46]. In addition to soluble Fas, alternatively spliced variants that contain the Fas ligandbinding domain but lack the transmembrane domain were detected more frequently in PBMC from silicosis patients than healthy donors [47]. Moreover, expression of the Decoy Receptor 3 (DcR3) molecule, whose function is known to be similar to that of soluble Fas and inhibits Fasmediated apoptosis by binding with the Fas ligand at extracellular areas, was higher in PBMC from silicosis patients than healthy donors [48]. All of these findings indicate that Fas-mediated apoptosis in lymphocytes from silicosis patients was inhibited by many molecules to a greater extent than that recorded for healthy donors [49].

It was assumed that responder $\mathrm{T}$ cells being stimulated by self/non-self antigens in silicosis patients are not exposed to Fas-mediated apoptosis, which results in their longer survival and chronic activation. These may include the self-recognizing clones that subsequently cause autoimmune diseases [49].

\section{Chronic activation of responder $\mathrm{T}$ cells}

As mentioned above, a longer survival and chronic activation occur in responder $\mathrm{T}$ cells of silicosis patients. We therefore decided to examine other activation markers in responder T cells in CD4 positive peripheral blood $\mathrm{T}$ cells or serum from silicosis patients, and compared results with those of cells and serum from healthy donors.

We first analyzed expression of the PD-1 (Programmed Death 1) gene. CD4 positive with CD25 positive or negative fractions from silicosis patients showed a higher PD-1 expression when compared with that of healthy donors [50].

In addition, the serum levels of soluble interleukin (IL)2 receptor (sIL-2R) were compared among healthy donors, silicosis and SSc patients. sIL-2R was initially considered a marker for $\mathrm{T}$ cell lineage malignancies such as $\mathrm{T}$ cell leukemia and lymphoma $[51,52]$. Thereafter, sIL-2R was evaluated as the activation marker for $\mathrm{T}$ cells under certain pathophysiological conditions such as autoimmune diseases. Several reports then demonstrated higher serum sIL2R levels for autoimmune disorders [53, 54].

We hypothesized that the condition of silicosis patients, even though not exhibiting symptoms of autoimmune disorders, may shift toward altered regulation of autoimmunity and occupy a condition between that of healthy donors and patients with autoimmune diseases. Thus, we measured serum sIL-2R levels in cases of silicosis [22]. Our results showed that these levels tended to be higher than those of healthy donors and lower than those of SSc patients, but the differences between groups were not significant. Alternatively, if we hypothesized the immunological alteration progressed from healthy donor (as normal) to silicosis (mild) and SSc (severe), these progression may be substitute as the number. Then, if we utilize immunological altering scales and assign healthy donors with a score of ' 1 ', silicosis patients with ' 2 ', and SSc with ' 3 ', we find a significant positive correlation between the serum sIL-2R level and this scale. To resolve the relationship between serum sIL-2R levels and respiratory or immunological parameters in silicosis patients, the correlations between many clinical parameters were analyzed. sIL-2R levels showed a positive correlation with serum ANA titers and titers for anti-Scl-70 autoantibody or anti-centromere autoantibody [22]. Multi-regression analysis was then performed to determine which parameters were related to serum sIL-2R levels. Our results showed that serum IgG levels and titers for anti-centromere autoantibody were factors that were related significantly to the levels of sIL-2R. Moreover, factor analysis including respiratory and immunological parameters showed that sIL-2R levels constructed the factor with serum IgG, serum-soluble Fas levels, and the CD25 positive rate in CD4 positive cells of peripheral blood. All of these findings indicated that upregulated sIL-2R in silicosis was the parameter for immunological alteration in silicosis patients, which may suggest the chronic activation of responder $\mathrm{T}$ cells [22].

Interestingly, forced expiratory volume $1.0 \quad(\mathrm{~s}) \%$ (FEV1.0), which is a marker of obstructive lung disease, was also extracted with sIL-2R when factor analysis was performed. The FEV1.0 was also extracted with serumsoluble Fas levels and the soluble/wild-type Fas mRNA expression ratio in PBMC from silicosis patients when another factor analysis was performed [22]. Although it was not fully understood why FEV1.0 showed similar characteristics with some immunological factors, a future investigation examining the relationship between respiratory and immunological progression in silicosis patients is needed to understand all of the pathophysiological aspects in silicosis [22].

Factor analysis also showed that there were two dominant factors in silicosis when all the respiratory and immunological clinical parameters were mixed in this analysis. One is recognized as a respiratory factor that includes exposure time, ILO classification, percent vital capacity and other elements, while the other is an 
immunological factor that includes serum $\operatorname{IgG}$, ANA titer, soluble Fas and other elements. Serum sIL-2R was not included in this analysis. Interestingly, approximately onefourth of patients were progressing to the alteration of autoimmunity, but better from a respiratory aspect, while a small percentage of patients showed opposite features, and most of the patients showed that both factors were similarly progressed. This finding indicated that there is a certain population of silicosis patients which does not progress toward a respiratory pathology, but becomes worse through immunological changes [55].

In the experimental setting, chronic activation in T cells was found when PBMC freshly isolated from healthy donors were co-cultivated with silica particles [56]. The lymphocytes gradually exhibited the early $\mathrm{T}$ cell activation marker, CD69. This supported the notion that silica particles certainly activate T lymphocytes. In this case, if the monocytes, which are important for recognition of silica particles as dangerous foreign entities, were deleted, the activation did not occur. Moreover, even if monocytes were presented with chrysotile, an asbestos fiber known as white asbestos, they did not induce the expression of CD69 [56].

\section{Chronic activation of regulatory $\mathrm{T}$ cells}

Regulatory $\mathrm{T}$ cells (Treg) have been identified and recognized as a very important population in CD4 positive $\mathrm{T}$ cells that regulate the activation of responder $\mathrm{T}$ cells and terminate the stimulation of $\mathrm{T}$ cells by self/non-self antigens [57-60]. A consideration of autoimmune disorders shows that the loss of quality or quantity of Treg may cause the long-lasting activation of responder $\mathrm{T}$ cells, which subsequently manifests altered regulation of autoimmunity and causes autoimmune diseases.

Treg is the CD4 and CD25 positive T cell population expressing the master transcription gene, FoxP3 (forkhead box P3) [57-60].

Since the condition of silicosis patients is often complicated with autoimmune disease, and the abovementioned findings indicated that altered regulation of autoimmunity was induced by silica exposure, the function of peripheral Treg fraction was first examined [21].

The inhibitory activity of peripheral blood CD4 and CD25 positive fractions derived from silicosis patients or healthy donors was compared using a mixed lymphocyte reaction assay. A CD4 positive $\mathrm{Cd} 25$ negative peripheral blood fraction was incubated with irradiated allo-PBMC with various ratios of auto-Treg fractions (Responder $\mathrm{T}$ :Treg $=1: 0,1 / 8,1 / 4,1 / 2$ and 1$)$. The proliferating activity of responder $\mathrm{T}$ cells measured by $3 \mathrm{H}$-thymidine incorporation showed that the inhibitory effects were significantly lower in Treg when the mixture ratio with responder $\mathrm{T}$ cells was $1: 1 / 4$ or $1 /: 1 / 2$ [21].
To explain this reduced inhibitory function of the peripheral CD4 and $\mathrm{Cd} 25$ positive fraction, it should be noted, as mentioned above, that responder $\mathrm{T}$ cells in silicosis patients were assumed to be chronically activated and of a longer survival. These activated cells express CD25 as the activation marker. Thus, there may be contamination in the CD4 and CD25 positive peripheral fraction in silicosis patients since, as described before, PD- 1 as the activation marker exhibited highly expressed mRNA levels in the CD4 and CD25 positive fraction of silicosis patients compared to that of healthy donors. We did not sort using FoxP3 positivity in this experiment because FoxP3 is located in the nucleus, and after staining the intra-nuclear molecule using permeabilization of cell surface membrane, these cells were not used in the bio-assay [21].

In addition to contamination of chronically activated responder $\mathrm{T}$ cells into the $\mathrm{CD} 4$ and $\mathrm{Cd} 25$ positive fraction, it may be possible to determine whether the number of real Treg is reduced. Reports indicate that the CD95/Fas molecule is upregulated when Treg is stimulated, and this is considered a kind of AICD because the inhibitory function to cease the activation of $T$ cells should also last longer [61, 62].

Thus, surface Fas expression in CD4, CD25 and FoxP3 positive $\mathrm{T}$ cells derived from silicosis patients and healthy donors was analyzed. Results showed that Fas expression was significantly higher in Treg from silicosis patients than healthy donors. In addition, Tregs from silicosis patients or healthy donors were cultivated with agonistic anti-Fas antibody, and our findings showed that the frequency and magnitude of apoptosis were significantly higher in Treg from silicosis patients than healthy donors [22].

Furthermore, freshly isolated PBMC from healthy donors were cultivated with silica particles and changes in the expression of CD25 and FoxP3 positive $\mathrm{T}$ cells were examined. Under these culture conditions, although the number of CD4 and CD25 positive cells did not change significantly, the CD4 and CD25 positive with FoxP3 positive fraction decreased, and the percentage of FoxP3 positive cells in CD25 positive cells was also reduced for 4 days of cultivation. These findings suggested that silica exposure causes chronic activation of responder T cells with CD25 novel expression, as well as chronic activation of Treg with earlier loss of Treg by Fas-mediated apoptosis [22].

The overall findings indicate that chronic activation of responder $\mathrm{T}$ cells and Treg occurred in the peripheral blood of silicosis patients by chronic and recurrent exposure to silica particles, and responder $\mathrm{T}$ cells may then survive for a longer period, whereas Treg may be lost by apoptosis (and is probably recruited from bone marrow) [22].

A consideration of the Fas-related molecules described above suggests that responder $\mathrm{T}$ cells may be the $\mathrm{T}$ cell fraction in which soluble Fas, other alternatively splicing variants, and DcR3 molecules are produced, and that Fas- 
Fig. 1 Schematic model of silica-induced alteration of immune cells

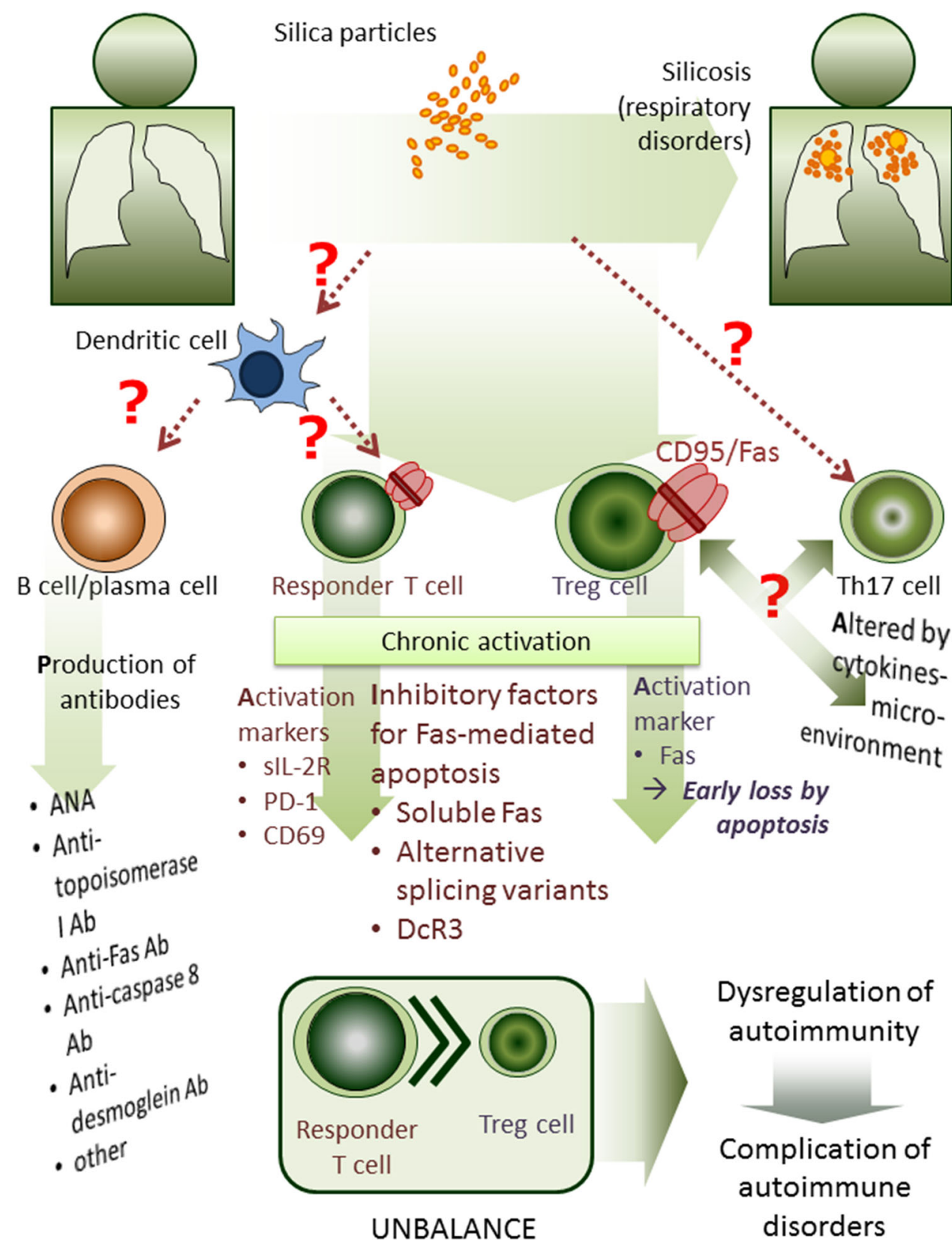

mediated apoptosis is suppressed. On the other hand, we also demonstrated that PBMC from silicosis patients showed decreased expression of physiological inhibitory molecules for Fas-mediated apoptosis such as i-flice, sentrin, survivine and inhibitor of caspase activated DNase (ICAD) [63]. These findings suggested that there are two subpopulations of $\mathrm{T}$ cells in silicosis PBMC. One comprises $\mathrm{T}$ cells resistant against Fas-mediated apoptosis and now recognized as chronically activated responder $\mathrm{T}$ cells. The other subpopulation manifested accelerated Fas-mediated apoptosis (and was also sensitive to functional antiFas autoantibody, as described above) and is now recognized as chronically activated Treg [49, 64-68].
Our findings indicate that the unbalance of Treg and responder $\mathrm{T}$ cells in silicosis patients resulted from chronic silica exposure. This alteration may subsequently result in the altered regulation of autoimmunity and appearance of autoimmune diseases in silicosis patients. The schematic model of silica-induced cellular and molecular alterations is shown in Fig. 1.

\section{Conclusions}

Th17 cells in CD4 positive $\mathrm{T}$ cells have recently been discovered and are thought to play an important role in the 
occurrence of autoimmune diseases. Moreover, the microenvironment defined by cytokines such as IL-6 and TGF- $\beta$ modified the polarization between Th17 and Treg $[69,70]$. These modifications may affect the immunological changes and occurrence of autoimmune disorders.

Although we have not yet investigated the effects of silica particles on differentiation, proliferation and functional changes of Th17 cells, or the cellular and molecular biological characterization of dendritic cells, these studies may contribute to a better understanding of the immunological effects of silica particles and silica-induced altered regulation of autoimmunity.

The findings shown in this review may support the clinical care of silicosis patients with regard to pulmonary pathology and immunological changes. Moreover, these findings may provide clues for a better understanding of the various autoimmune diseases such as SSc and ANCArelated vasculitis. Beneficial modifications concerning nutritional factors, physical exercise, and the living environment such as improved air quality of the atmosphere or in rooms for the immune system, may be useful in preventing autoimmune disorders.

Acknowledgments The authors appreciate the assistance of all the previous members of the Department of Hygiene, Kawasaki Medical School, Prof. Ayako Ueki, Drs. Fuminori Hyodoh, Akiko TakataTomokuni, Yoshie Miura, Shuko Murakami and Yasuhiko Kawaka$\mathrm{mi}$, and especially appreciate all the technical assistance given by Ms. Tamayo Hatayama, Shoko Yamamoto, Haruko Sakaguchi, Naomi Miyahara, Minako Katoh, Misao Kuroki, Tomoko Sueishi, Keiko Kimura, Yoshiko Yamashita and Satomi Hatada.

Conflict of interest The authors declare no conflict of interest.

\section{References}

1. Cullinan P, Reid P. Pneumoconiosis. Prim Care Respir J. 2013;22:249-52.

2. Laney AS, Weissman DN. The classic pneumoconioses: new epidemiological and laboratory observations. Clin Chest Med. 2012;33:745-58.

3. Nukushina J. Japanese earthquake victims are being exposed to high density of asbestos. We need protective masks desperately. Epidemiol Prev. 1995;19:226-7.

4. van Orden DR, Lee RJ, Bishop KM, Kahane D, Morse R. Evaluation of ambient asbestos concentrations in buildings following the Loma Prieta earthquake. Regul Toxicol Pharmacol. 1995;21:117-22.

5. Caplan A. Rheumatoid disease and pneumoconiosis (Caplan's syndrome). Proc R Soc Med. 1959;52:1111-3.

6. Caplan A, Payne A, Payne RB, Withey JL. A broader concept of Caplan's syndrome related to rheumatoid factors. Thorax. 1962;17:205-12.

7. Costallat LT, De Capitani EM, Zambon L. Pulmonary silicosis and systemic lupus erythematosus in men: a report of two cases. Joint Bone Spine. 2002;69:68-71.

8. Yamazaki S, Yoshiike F, Hirai K, Kakegawa T, Ikeda M, Nagata A, et al. Silica-associated systemic lupus erythematosus in an elderly man. Intern Med. 2007;46:1867-71.
9. Haustein UF, Anderegg U. Silica induced scleroderma-clinical and experimental aspects. J Rheumatol. 1998;25:1917-26.

10. Iannello S, Camuto M, Cantarella S, Cavaleri A, Ferriero P, Leanza A, Milazzo P, Belfiore F. Rheumatoid syndrome associated with lung interstitial disorder in a dental technician exposed to ceramic silica dust. A case report and critical literature review. Clin Rheumatol. 2002;21:76-81.

11. Tervaert JW, Stegeman CA, Kallenberg CG. Silicon exposure and vasculitis. Curr Opin Rheumatol. 1998;10:12-7.

12. Saeki T, Fujita N, Kourakata H, Yamazaki H, Miyamura S. Two cases of hypertrophic pachymeningitis associated with myeloperoxidase antineutrophil cytoplasmic autoantibody (MPOANCA)-positive pulmonary silicosis in tunnel workers. Clin Rheumatol. 2004;23:76-80.

13. Uber CL, McReynolds RA. Immunotoxicology of silica. Crit Rev Toxicol. 1982;10:303-19.

14. Steenland K, Goldsmith DF. Silica exposure and autoimmune diseases. Am J Ind Med. 1995;28:603-8.

15. Vera-Lastra O, Medina G, Del Pilar Cruz-Dominguez M, Jara LJ, Shoenfeld Y. Autoimmune/inflammatory syndrome induced by adjuvants (Shoenfeld's syndrome): clinical and immunological spectrum. Expert Rev Clin Immunol. 2013;9:361-73.

16. Otsuki T, Maeda M, Murakami S, Hayashi H, Miura Y, Kusaka M, Nishimura $Y$, et al. Immunological effects of silica and asbestos. Cell Mol Immunol. 2007;4:261-8.

17. Maeda M, Miura Y, Nishimura Y, Murakami S, Hayashi H, Kumagai $\mathrm{N}$, et al. Immunological changes in mesothelioma patients and their experimental detection. Clin Med Circ Respir Pulm Med. 2008;2:11-7.

18. Miura Y, Nishimura Y, Maeda M, Murakami S, Hayashi H, Fukuoka $\mathrm{K}$, et al. Immunological alterations found in mesothelioma patients and supporting experimental evidence. Environ Health Prev Med. 2008;13:55-9.

19. Murakami S, Nishimura Y, Maeda M, Kumagai N, Hayashi H, Chen Y, et al. Cytokine alteration and speculated immunological pathophysiology in silicosis and asbestos-related diseases. Environ Health Prev Med. 2009;14:216-22.

20. ILO. Guideline for the use of the ILO international classification of radiographs of pneumoconiosis, Revised Edition 2000. ILO, Occupational Safety and Health series. No. 22. Geneva, Switzerland. 2002.

21. Wu P, Miura Y, Hyodoh F, Nishimura Y, Hatayama T, Hatada S, et al. Reduced function of CD4 $+25+$ regulatory $\mathrm{T}$ cell fraction in silicosis patients. Int J Immunopathol Pharmacol. 2006;19:357-68.

22. Hayashi H, Maeda M, Murakami S, Kumagai N, Chen Y, Hatayama $\mathrm{T}$, et al. Soluble interleukin-2 receptor as an indicator of immunological disturbance found 388 in silicosis patients. Int $\mathbf{J}$ Immunopathol Pharmacol. 2009;22:53-62.

23. Ueki A, Isozaki Y, Tomokuni A, Tanaka S, Otsuki T, Kishimoto $\mathrm{T}$, et al. Autoantibodies detectable in the sera of silicosis patients. The relationship between the anti-topoisomerase I antibody response and HLA-DQB $1 * 0402$ allele in Japanese silicosis patients. Sci Total Environ. 2001;270:141-8.

24. Ueki A, Isozaki Y, Tomokuni A, Ueki H, Kusaka M, Tanaka S, et al. Different distribution of HLA class II alleles in anti-topoisomerase I autoantibody responders between silicosis and systemic sclerosis patients, with a common distinct amino acid sequence in the HLA-DQB1 domain. Immunobiology. 2001;204:458-65.

25. Tomokuni A, Otsuki T, Sakaguchi H, Isozaki Y, Hyodoh F, Kusaka M, et al. Detection of anti-topoisomerase I autoantibody in patients with silicosis. Environ Health Prev Med. 2002;7:7-10.

26. Ueki A, Isozaki Y, Tomokuni A, Otsuki T, Hyodoh F, Sakaguchi $\mathrm{H}$, et al. Is the anti-topoisomerase I autoantibody response associated with a distinct amino acid sequence in the HLA-DQbeta1 domain? Arthritis Rheum. 2001;44:491-2. 
27. Takata-Tomokuni A, Ueki A, Shiwa M, Isozaki Y, Hatayama T, Katsuyama $\mathrm{H}$, et al. Detection, epitope-mapping and function of anti-Fas autoantibody in patients with silicosis. Immunology. 2005;116:21-9.

28. Nagata S. Fas and Fas ligand: a death factor and its receptor. Adv Immunol. 1994;57:129-44.

29. Nagata S, Golstein P. The Fas death factor. Science. 1995;267: 1449-56.

30. Bleesing JJ. Autoimmune lymphoproliferative syndrome (ALPS). Curr Pharm Des. 2003;9:265-78.

31. Rieux-Laucat F, Le Deist F, Fischer A. Autoimmune lymphoproliferative syndromes: genetic defects of apoptosis pathways. Cell Death Differ. 2003;10:124-33.

32. Peter ME, Krammer PH. Mechanisms of CD95 (APO-1/Fas)mediated apoptosis. Curr Opin Immunol. 1998;10:545-51.

33. Cohen GM. Caspases: the executioners of apoptosis. Biochem J. 1997;326:1-16.

34. Ueki A, Isozaki Y, Tomokuni A, Hatayama T, Ueki H, Kusaka $\mathrm{M}$, et al. Intramolecular epitope spreading among anti-caspase-8 autoantibodies in patients with silicosis, systemic sclerosis and systemic lupus erythematosus, as well as in healthy individuals. Clin Exp Immunol. 2002;129:556-61.

35. Ueki A, Isozaki Y, Kusaka M. Anti-caspase-8 autoantibody response in silicosis patients is associated with HLA-DRB1, DQB1 and DPB1 alleles. J Occup Health. 2005;47:61-7.

36. Ueki H, Kohda M, Nobutoh T, Yamaguchi M, Omori K, Miyashita $\mathrm{Y}$, et al. Antidesmoglein autoantibodies in silicosis patients with no bullous diseases. Dermatology. 2001;202:16-21.

37. Alderson MR, Lynch DH. Receptors and ligands that mediate activation-induced death of T cells. Springer Semin Immunopathol. 1998;19:289-300.

38. Mountz JD, Wu J, Zhou T, Hsu HC. Cell death and longevity: implications of Fas-mediated apoptosis in T-cell senescence. Immunol Rev. 1997;160:19-30.

39. Cascino I, Papoff G, Eramo A, Ruberti G. Soluble Fas/Apo-1 splicing variants and apoptosis. Front Biosci. 1996;1:d12-8.

40. Cheng J, Zhou T, Liu C, Shapiro JP, Brauer MJ, Kiefer MC, et al. Protection from Fas-mediated apoptosis by a soluble form of the Fas molecule. Science. 1994;263:1759-62.

41. Knipping E, Krammer PH, Onel KB, Lehman TJ, Mysler E, Elkon KB. Levels of soluble Fas/APO-1/CD95 in systemic lupus erythematosus and juvenile rheumatoid arthritis. Arthritis Rheum. 1995;38:1735-7.

42. Tokano Y, Miyake S, Kayagaki N, Nozawa K, Morimoto S, Azuma $\mathrm{M}$, et al. Soluble Fas molecule in the serum of patients with systemic lupus erythematosus. J Clin Immunol. 1996;16:261-5.

43. Jodo S, Kobayashi S, Kayagaki N, Ogura N, Feng Y, Amasaki Y, et al. Serum levels of soluble Fas/APO-1 (CD95) and its molecular structure in patients with systemic lupus erythematosus (SLE) and other autoimmune diseases. Clin Exp Immunol. 1997;107:89-95.

44. Nozawa K, Kayagaki N, Tokano Y, Yagita H, Okumura K, Hasimoto H. Soluble Fas (APO-1, CD95) and soluble Fas ligand in rheumatic diseases. Arthritis Rheum. 1997;40:1126-9.

45. Tomokuni A, Aikoh T, Matsuki T, Isozaki Y, Otsuki T, Kita S, et al. Elevated soluble Fas/APO-1 (CD95) levels in silicosis patients without clinical symptoms of autoimmune diseases or malignant tumours. Clin Exp Immunol. 1997;110:303-9.

46. Otsuki T, Sakaguchi H, Tomokuni A, Aikoh T, Matsuki T, Kawakami Y, et al. Soluble Fas mRNA is dominantly expressed in cases with silicosis. Immunology. 1998;94:258-62.

47. Otsuki T, Sakaguchi H, Tomokuni A, Aikoh T, Matsuki T, Isozaki $\mathrm{Y}$, et al. Detection of alternatively spliced variant messages of Fas gene and mutational screening of Fas and Fas ligand coding regions in peripheral blood mononuclear cells derived from silicosis patients. Immunol Lett. 2000;72:137-43.
48. Otsuki T, Tomokuni A, Sakaguchi H, Aikoh T, Matsuki T, Isozaki Y, et al. Over-expression of the decoy receptor 3 (DcR3) gene in peripheral blood mononuclear cells (PBMC) derived from silicosis patients. Clin Exp Immunol. 2000;119:323-7.

49. Otsuki T, Miura Y, Nishimura Y, Hyodoh F, Takata A, Kusaka $\mathrm{M}$, et al. Alterations of Fas and Fas-related molecules in patients with silicosis. Exp Biol Med (Maywood). 2006;231:522-33.

50. Hayashi H, Miura Y, Maeda M, Murakami S, Kumagai N, Nishimura $\mathrm{Y}$, et al. Reductive alteration of the regulatory function of the $\mathrm{CD} 4(+) \mathrm{CD} 25(+) \mathrm{T}$ cell fraction in silicosis patients. Int $\mathrm{J}$ Immunopathol Pharmacol. 2010;23:1099-109.

51. Greene WC, Leonard WJ, Depper JM, Nelson DL, Waldmann TA. The human interleukin-2 receptor: normal and abnormal expression in $\mathrm{T}$ cells and in leukemias induced by the human T-lymphotropic retroviruses. Ann Intern Med. 1986;105:560-72.

52. Pizzolo G, Chilosi M, Semenzato G. The soluble interleukin-2 receptor in haematological disorders. Br J Haematol. 1987;67: $377-80$.

53. Zerler B. The soluble interleukin-2 receptor as a marker for human neoplasia and immune status. Cancer Cells. 1991;3: 471-9.

54. Witkowska AM. On the role of sIL-2R measurements in rheumatoid arthritis and cancers. Mediat Inflamm. 2005;2005:121-30.

55. Otsuki T, Ichihara K, Tomokuni A, Sakaguchi H, Aikoh T, Matsuki T, et al. Evaluation of cases with silicosis using the parameters related to Fas-mediated apoptosis. Int J Mol Med. 1999;4:407-11.

56. Wu P, Hyodoh F, Hatayama T, Sakaguchi H, Hatada S, Miura Y, et al. Induction of CD69 antigen expression in peripheral blood mononuclear cells on exposure to silica, but not by asbestos/ chrysotile-A. Immunol Lett. 2005;98:145-52.

57. Sakaguchi S. Regulatory T cells: key controllers of immunologic self-tolerance. Cell. 2000;101:455-8.

58. Sakaguchi S, Sakaguchi N, Shimizu J, Yamazaki S, Sakihama T, Itoh $\mathrm{M}$, et al. Immunologic tolerance maintained by $\mathrm{CD} 25+$ $\mathrm{CD} 4$ + regulatory $\mathrm{T}$ cells: their common role in controlling autoimmunity, tumor immunity, and transplantation tolerance. Immunol Rev. 2001;182:18-32.

59. Horwitz DA, Zheng SG, Gray JD, Wang JH, Ohtsuka K, Yamagiwa S. Regulatory $\mathrm{T}$ cells generated ex vivo as an approach for the therapy of autoimmune disease. Semin Immunol. 2004;16: 135-43.

60. Sakaguchi S. Naturally arising Foxp3-expressing CD25+ CD4 + regulatory T cells in immunological tolerance to self and non-self. Nat Immunol. 2005;6:345-52.

61. Fritzsching B, Oberle N, Eberhardt N, Quick S, Haas J, Wildemann $B$, et al. In contrast to effector $T$ cells, CD4 + $\mathrm{CD} 25$ + FoxP3 + regulatory $\mathrm{T}$ cells are highly susceptible to CD95 ligand- but not to TCR-mediated cell death. J Immunol. 2005;175:32-6.

62. Fritzsching B, Oberle N, Pauly E, Geffers R, Buer J, Poschl J, et al. Naive regulatory T cells: a novel subpopulation defined by resistance toward CD95L-mediated cell death. Blood. 2006;108: 3371-8.

63. Otsuki T, Tomokuni A, Sakaguchi H, Hyodoh F, Kusaka M, Ueki A. Reduced expression of the inhibitory genes for Fas-mediated apoptosis in silicosis patients. J Occup Health. 2000;42:163-8.

64. Maeda M, Nishimura Y, Kumagai N, Hayashi H, Hatayama T, Katoh M, et al. Altered regulation of the immune system caused by silica and asbestos. J Immunotoxicol. 2010;7:268-78.

65. Lee S, Hayashi H, Maeda M, Chen Y, Matsuzaki H, TakeiKumagai N, et al. Environmental factors producing autoimmune altered regulation-chronic activation of $\mathrm{T}$ cells caused by silica exposure. Immunobiology. 2012;217:743-8.

66. Takei-Kumagai N, Lee S, Matsuzaki H, Hayashi H, Maeda M, Nishimura Y, et al. Immunological effects of silica. In: Kretsinger 
RH, Uversky VN, Permyakov EA, editors. Encyclopedia of metalloproteins. New York: Springer Science + Business Media; 2013. pp. 1965-71.

67. Kumagai N, Hayashi H, Maeda M, Miura Y, Nishimura Y, Matsuzaki $\mathrm{H}$, et al. Immunological effects of silica and related altered regulation of autoimmunity. In: Mavragani $\mathrm{CP}$, editor. Autoimmune disorders-pathogenetic aspects. Croatia: InTech Open Access Publisher; 2011. doi:10.5772/19218.

68. Lee S, Maeda M, Hayashi H, Matsuzaki H, Kumagai-Takei N, Nishimura Y, et al. Immunostimulation by silica particles and the development of autoimmune altered regulation. In: Duc H, editor. Immunostimulation. Croatia: InTech Open Access Publisher; 2014. doi: $10.5772 / 57544$.

69. Weaver CT, Harrington LE, Mangan PR, Gavrieli M, Murphy KM. Th17: an effector CD4 T cell lineage with regulatory $\mathrm{T}$ cell ties. Immunity. 2006;24:677-88.

70. Bi Y, Liu G, Yang R. Th17 cell induction and immune regulatory effects. J Cell Physiol. 2007;211:273-8. 